\title{
Smoking harms surgical procedures
}

A new study has found that smoking damages the long-term stability of certain oral surgical procedures. The research published recently in the Journal of Periodontology (2007; 78: 1702-1707) found that smokers had less desirable long-term results following periodontal plastic surgery than non-smokers.

The study followed ten smokers and ten non-smokers for two years to evaluate the effects of cigarette smoke on the long-term outcomes of a treatment to help soft tissue reattach to the root surface of the teeth.

After two years, residual gum recession around the area which received the surgery was greater in smokers as compared to nonsmokers. Studies have shown that smoking can impair the body's ability to heal itself immediately after surgery, but this most recent study also showed that when a patient has periodontal plastic surgery, smoking can restrict the ability of that procedure to stay intact over a long period of time.

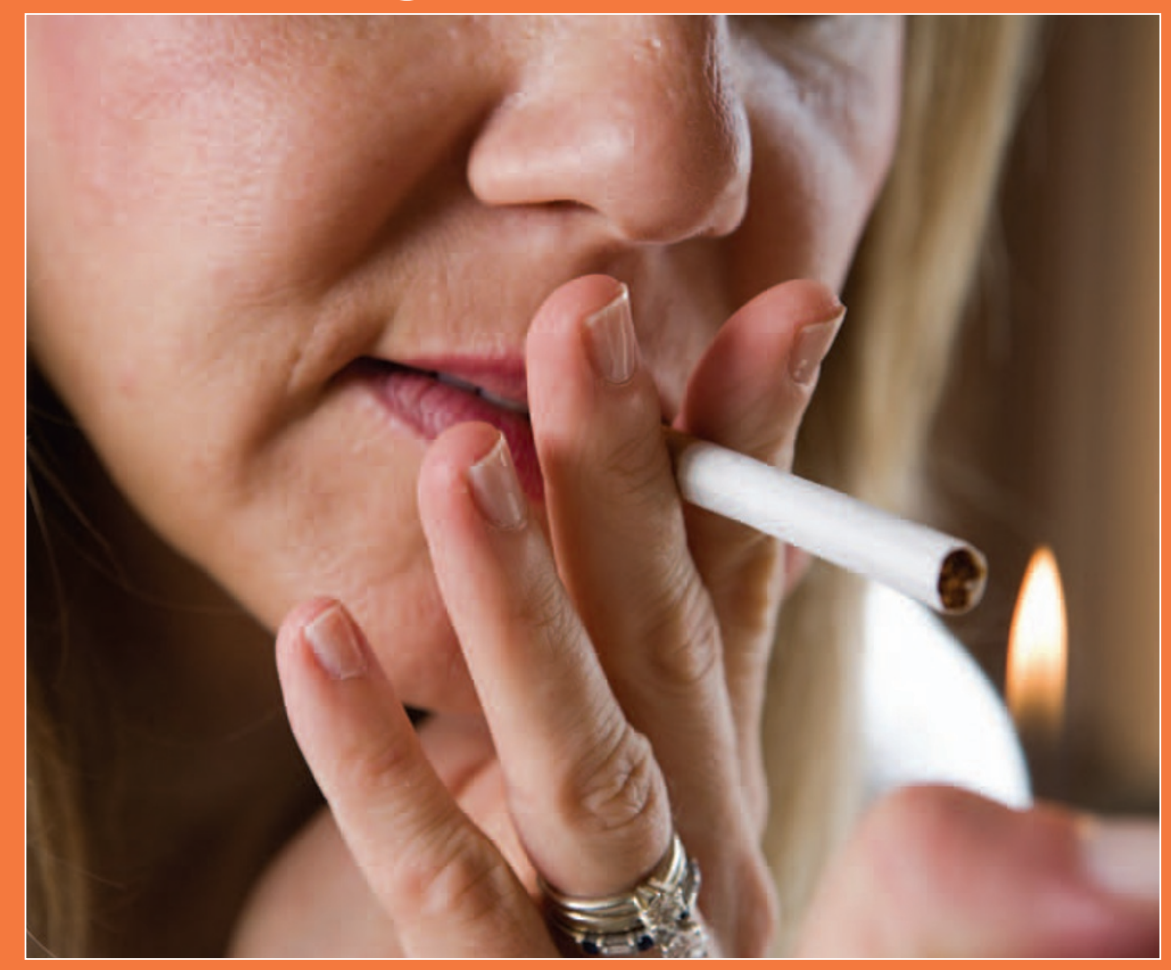

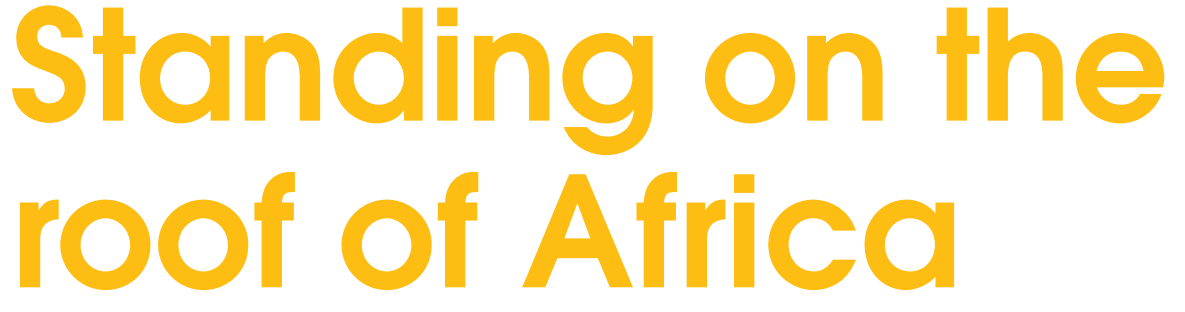

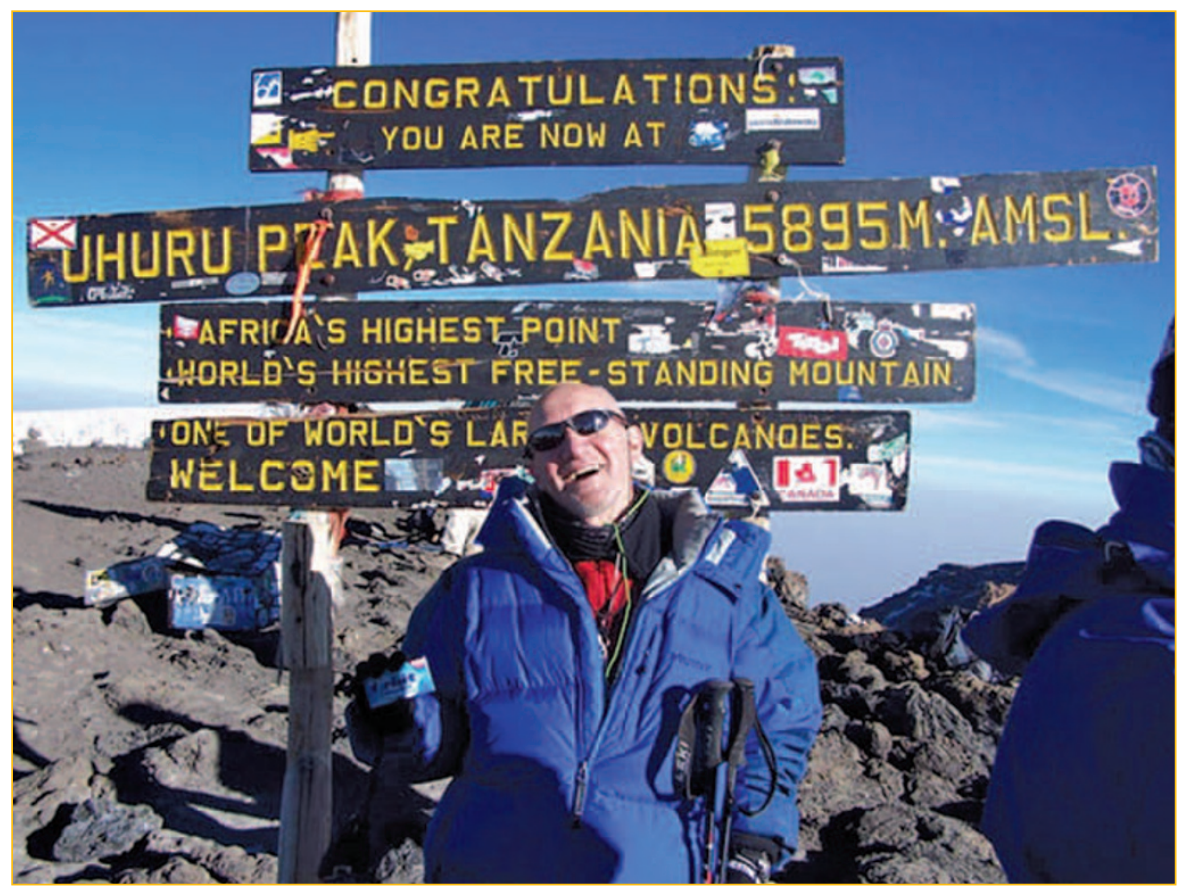

08

vital
Chichester based dental charity Bridge2Aid, which works in Mwanza, Tanzania, took 38 brave individuals to Africa recently to scale the heights of the famous 5,895 metre high Mount Kilimanjaro.

The 38 climbers, ranging in age from 18-65,

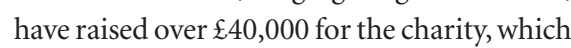
is vital to support their ongoing dental and social care programmes. Fundraising events organised by participants ranged from the sublime to the ridiculous. 'People stretched their imaginations to the limit on our behalf - they organised curry nights, murder mystery parties and even went to work in fancy dress!' said Operations Director Mark Topley. 'We have been overwhelmed by the enthusiasm and achievement of those taking part.'

The charity has now launched its next challenge: climbing the Three Peaks of Yorkshire, Ingleborough, Pen-y-ghent and Whernside, in under 12 hours. Under the slogan of '2008: 52 weekends - Make One Count', motivated individuals or groups are invited to take up this challenge on an organised weekend next May, June, July or September.

For more information on Bridge2Aid's work, or to request information about its forthcoming challenge, visit www.bridge2aid. org or email jennie@bridge2aid.org. 